\title{
A construção da identidade gerencial dos gestores da alta administração de universidades federais em Minas Gerais
}

\section{The managerial identity construction of top managers at federal universities in Minas Gerais}

Angelo Brigato Ésther ${ }^{1}$

Marlene Catarina de Oliveira Lopes Melo ${ }^{2}$

\begin{abstract}
Resumo
Identidade emerge como conceito central - especialmente no que concerne à figura do gerente enquanto ator e enquanto categoria diferenciada - e diz respeito às representações que os indivíduos elaboram sobre si mesmos e sobre os outros, construídas como resultado dos diversos processos de socialização. As organizações constituem um espaço privilegiado de construção de identificações e de definições de si e dos outros. Assim, este artigo visa discutir como os gestores da alta administração de universidades federais constroem sua identidade gerencial. A pesquisa foi realizada com reitores, vicereitores e pró-reitores de oito universidades federais localizadas no estado de Minas Gerais. Os dados foram obtidos por meio de entrevistas episódicas e complementados por pesquisa documental. Para a análise dos dados, utilizou-se, basicamente, a técnica da análise temática. Os resultados mostram que os gestores vivem num contexto em que os ideais históricos da universidade são contrapostos aos ideais econômicos de produtividade, eficiência e resultados, bem como num ambiente em que têm de articular diversos interesses e pontos de vista sobre a instituição e sua gestão, resultando na configuração de uma identidade múltipla (políticos, gestores e professores), relativamente frágil e, por vezes, contraditória.
\end{abstract}

Palavras-chave: identidade gerencial; altos gestores universitários; universidades.

\begin{abstract}
Identity emerges as a central concept when referring to manager as an actor and a differentiated professional category, and concerns to representations of the individuals about themselves and the others, constructed as a result of several socialization processes. Organizations are a privileged space of identification and self-concept construction. This paper aims at discussing how top managers at federal universities in Minas Gerais construct their managerial identities. Data were collected by episodical interviews with the top managers of eight federal universities in Minas Gerais, and documental research, and were analyzed by the thematic analysis. The results show that managers live in a context of conflict between the historical mission of the university and the economic and managerial logics of productivity, efficiency and outcome. They also live in a context with many political interests. The result is the configuration of a multiple and relatively fragile identity (politicians, managers and academics), which is contradictory sometimes.
\end{abstract}

Keywords: managerial identity; top managers of universities; federal universities.

\footnotetext{
1 Doutor em Administração pelo CEPEAD/FACE/UFMG. Professor da Faculdade de Economia e Administração da Universidade Federal de Juiz de Fora (MG). E-mail: angelo.esther@ufjf.edu.br. Endereço: Rua José Thomé de Souza5/504 - Itatiaia - Juiz de Fora/MG -CEP: 36037030 - Brasil.

2 Doutora em Ciências das Organizações pela Universidade de Paris IX (França). Diretora e Professora da Faculdade Novos Horizontes (MG). E-mail: lenemelo@unihorizontes.br. Rua Alvarenga Peixoto, 1270 - Santo Agostinho - Belo Horizonte - Minas Gerais.Brasil - CEP: 30180121
}

Artigo aceito em setembro de 2007 e aceito em novembro de 2007 


\section{Introdução}

O estudo sobre trabalho gerencial vem ganhando importância a cada dia. Tradicionalmente, as pesquisas e publicações privilegiam determinadas variáveis e tipos de abordagem, notadamente de inspiração comportamentalista e funcionalista. No entanto, a primeira dificuldade que surge ao estudar o trabalho gerencial é definir o que significa "ser gerente". Há uma grande diversidade de posicionamentos sobre os desafios que se impõem aos gerentes e sobre quais são exatamente as características e habilidades que precisam ter para exercer suas funções.

O trabalho gerencial é repleto de ambigüidades, contradições, dilemas e dificuldades intrínsecas à natureza da função. E, ao contrário das abordagens tradicionais, a gestão pode ser entendida como uma prática social, o que recoloca o sujeito no centro das análises (REED, 1997). Por sua vez, o estudo do trabalho gerencial no interior das universidades ainda é precário e insuficiente, especialmente sob o enfoque que se pretende adotar neste trabalho. Embora haja diversos estudos e publicações sobre a gestão universitária, o levantamento bibliográfico não identificou nenhuma pesquisa que focasse a construção da identidade dos gestores daquelas instituições. Tal é a contribuição que se espera alcançar neste estudo, à medida que o tema é discutido, tomando-se como referência o ponto de vista dos sujeitos da ação, ou seja, reitores, vice-reitores e pró-reitores das instituições universitárias escolhidas.

A despeito de as concepções acerca da identidade serem diversas, em geral, elas dizem respeito às representações que os indivíduos elaboram sobre si mesmos e os outros, sendo construídas na relação do indivíduo com o outro (indivíduo, grupo ou organização, por exemplo), como resultado dos diversos processos de socialização (DUBAR, 1997), sendo as organizações um espaço privilegiado de construção de identificações e de definições de si e dos outros (SAINSAULIEU, 1997).

Diante do exposto, percebe-se que os gestores têm de construir uma forma própria de atuação gerencial, o que remete ao objetivo central aqui abordado: compreender como os reitores de universidades federais constroem sua identidade gerencial. Para viabilizar o objetivo proposto, a pesquisa foi realizada com gestores da alta administração de oito universidades federais localizadas no estado de Minas Gerais. Estas foram escolhidas em função de sua representatividade na região e no país - pertencem ao estado que possui o maior número de universidades federais instaladas -, bem como pela possibilidade de acesso que apresentam. Foram entrevistados todos os reitores, vice-reitores e dois pró-reitores de cada instituição, totalizando trinta e dois sujeitos.

\section{Trabalho e identidade gerenciais}

Atualmente, com a crescente influência que as organizações assumiram na sociedade - a ponto de Chanlat (2000) falar em sociedade "managerialista" -, a função gerencial é cada vez mais exposta, atribuindo-se a ela uma maior importância pelo sucesso de suas organizações. Nesse contexto, é possível perceber por que a literatura e a mídia, em geral, tendem a atribuir uma importância extrema às organizações - em especial às empresas -, atribuindo-lhes, muitas vezes, uma identidade divina, em que a figura do gerente transforma-se numa figura deificada para a sociedade (AKTOUF, 1996). No entanto, apesar da imagem deificada e glorificada do gerente, diversos estudos e pesquisas mostram o quanto a prática gerencial é complexa e repleta de incertezas, ambigüidades, contradições e dilemas (HILL, 1993; REED, 1997; MELO, 1994a, 1994b, 1999; DAVEL; VERGARA, 2001; ESTHER; MELO, 2004; DAVEL; MELO, 2005), contrariamente aos estudos da chamada "escola clássica".

Hill (1993) mostra, especialmente, os conflitos e ambigüidades que o indivíduo encontra e enfrenta durante o processo de construção de sua identidade gerencial ao longo do primeiro ano no cargo. Tais ambigüidades decorrem do fato de que os indivíduos, pelo menos nos casos estudados, são levados a ocupar cargos gerenciais sem nenhum tipo de preparação específica. Além disso, as expectativas dos gerentes são, inicialmente, até mesmo contraditórias em relação às expectativas dos subordinados, colegas e superiores. 
Reed (1997), adotando a perspectiva praxeológica, faz uma síntese dos diversos campos de análise dos estudos sobre gestão, assumindo que, nas visões mais tradicionais,

[...] os gestores tornam-se simplesmente agentes de imperativos funcionais, produzidos fora das práticas sociais em que se acham quotidianamente envolvidos. Enquanto portadores de uma racionalidade instrumental, ou enquanto representantes públicos da arte de fazer política organizacional, ou ainda como joguetes de forças sociais inexoráveis, os gestores perdem qualquer direito de compreensão sobre si próprios e de defesa da sua identidade cultural (REED, 1997, p. 22).

Reed (1997) define a gestão como prática social, considerando em sua análise os níveis institucional, organizacional e comportamental, na medida em que diz respeito à ação de indivíduos e grupos dentro de determinada organização e de um contexto macroestrutural. Vista dessa maneira, a gestão traz à tona as ambigüidades e a complexidade da prática da função gerencial, ao articular as diversas dimensões que a envolvem.

Ésther e Melo (2004) analisam o trabalho e os dilemas enfrentados pelos gerentes de uma grande empresa de informática: atender às demandas organizacionais versus sentir-se pressionado por seus subordinados; tornar sua organização mais eficiente e eficaz, mais racionalizada versus tornar-se desnecessário ou obsoleto; fazer algo diferente versus ser reconhecido socialmente e pelos superiores; sentir seus desejos e pulsões versus ter de comportar-se de forma racional; e ser criativo e produtivo versus ser limitado pela hierarquia e pela cultura organizacional.

Davel e Melo (2005) compilam e analisam diversas visões sobre as singularidades e os dilemas do trabalho gerencial. Em linhas gerais, concluem que a ação gerencial é dinâmica e carregada de ambivalência, instabilidade e contradição, as quais permeiam as práticas gerenciais. Nesse contexto, a identidade do gerente é construída sob tensão, e aprender a enfrentar esta tensão está no âmago da transformação de um indivíduo em gerente.

Entre as diversas abordagens acerca da identidade, destaca-se a de um dos autores mais influentes, Erik Erikson, para quem a identidade possui duas dimensões centrais: trata-se de um processo localizado "no âmago do indivíduo" e, entretanto, também no "núcleo central da sua cultura coletiva" (ERIKSON, 1987, p.21). Em outras palavras, explica o autor:

[...] a formação da identidade emprega um processo de reflexão e observação simultâneas, um processo que ocorre em todos os níveis de funcionamento mental, pelo qual o indivíduo se julga a si próprio à luz daquilo que percebe ser a maneira como os outros o julgam, em comparação com eles próprios e com uma tipologia que é significativa para eles; enquanto que ele julga a maneira como eles o julgam, à luz do modo como se percebe a si próprio em comparação com os demais e com os tipos que se tornaram importantes para ele. (ERIKSON, 1987, p. 21)

Este processo é dinâmico e evolucionário (e nem sempre consciente), começa no nascimento, encontra sua crise normativa no período da adolescência, é determinado (de múltiplas maneiras) pelo que aconteceu antes e determina, em grande medida, parte do que ocorrerá depois (ERIKSON, 1987). Assim, o autor chama a atenção para o aspecto histórico-temporal, ou seja, a identidade é construída e reconstruída ao longo da vida, e é esta luta para estabelecer uma clara identidade que consiste a "crise de identidade".

Na psicologia social, Tajfel é o primeiro a relacionar o conceito de identidade social (HOGG; TERRY, 2000) ao autoconceito. Para o autor, a identidade social é "aquela parte (grifo nosso) do autoconceito dos indivíduos que deriva de seu conhecimento de seu pertencimento a um grupo (ou grupos) social, bem como do valor e da significação emocional deste pertencimento" (TAJFEL, 1982, p. 24). 
De modo geral, para a teoria da identidade social (TIS), as pessoas tendem a classificar a si e aos outros de acordo com várias categorias sociais, tais como pertencimento organizacional e afiliação religiosa. Esta classificação social possui duas funções básicas, segundo Ashforth; Mael (1998):

a) segmenta cognitivamente e ordena o ambiente social, provendo o indivíduo de um meio sistemático de definir os outros. Uma pessoa é designada pelas características prototípicas pelas quais é classificada, embora nem sempre a designação seja confiável ou segura;

b) habilita o indivíduo a se localizar ou a se definir no ambiente social. De acordo com a TIS, o autoconceito é composto pela identidade pessoal (envolvendo as características idiossincráticas, como habilidades, interesses, trato psicológico e atributos físicos) e pela identidade social envolvendo classificações do grupo saliente.

A pessoa percebe a si como um membro real ou simbólico de determinado grupo e o destino do grupo como sendo o seu. Essa percepção de ser um ou de pertencer a algum grupo humano consiste na identificação social, e esta responde parcialmente à pergunta: Quem sou eu?

Assim, o conceito de identificação é chave, pois se refere ao sentimento de pertencimento a uma categoria social (Brown, 1997; ashforth; MAEL, 1998). A identidade da organização manifesta-se nas ações dos indivíduos, que "agem como a organização" quando incorporam valores, crenças e objetivos da coletividade (Brown, 1997), numa espécie de reificação da organização (ashforth; MAEL, 1998).

A psicossociologia, uma vertente da psicologia social, adota o conceito freudiano de múltiplas identificações simultâneas, que admite que cada indivíduo constrói seu ideal de eu segundo os modelos mais variados. Ou seja, cada indivíduo participa de numerosos grupos, ligado por vínculos de identificação em muitos sentidos. Por ser uma construção no tempo, a identidade, portanto, não possui as características de constância e permanência.

Além disso, a identidade também não é uma unidade, na medida em que diversos mecanismos psíquicos operam sobre o indivíduo, sejam eles conscientes ou inconscientes. Pelo simples fato de o inconsciente exercer um papel enorme na maneira de se viver e de ele não estar submetido aos mesmos processos do eu consciente, este último não pode ser considerado como o sujeito da enunciação e da ação. De certo modo, a identidade é uma espécie de ilusão, à medida que o indivíduo não conhece o "eu inconsciente". Admite-se que a identidade evolui, mas mantém certo grau de coerência. No entanto, não se trata de uma essência, posto que a identidade não é constante nem permanente, uma vez que se trata de uma construção no tempo (ENRIQUEZ, 1994).

Como a identidade é considerada num contexto específico e sempre em relação a um outro, isso implica levar em conta que o indivíduo normalmente pertence a um ou a diversos grupos. Cada grupo só se constitui em torno de uma ação a realizar, de um projeto a ser realizado ou de uma tarefa que precisa ser cumprida. Assim, um projeto comum implica a existência de um sistema de valores interiorizado pelos indivíduos do grupo, o que permite ao projeto suas características dinâmicas (a passagem do plano à ação). Tal sistema de valores deve apoiar-se num imaginário social comum, ou numa representação coletiva. Por imaginário social o autor entende que

[...] só podemos agir quando temos uma certa maneira de nos representar aquilo que somos, aquilo que queremos vir a ser, aquilo que queremos fazer e em que tipo de sociedade ou organização desejamos intervir. Para serem operantes, tais representações devem não só ser intelectualmente pensadas, mas afetivamente sentidas. Não se trata unicamente de querer coletivamente; trata-se de sentir coletivamente, de experimentar a mesma necessidade de transformar um sonho ou uma fantasia em realidade cotidiana e de se munir dos meios para conseguir isso (ENRIQUEZ, 1994, p. 57).

Portanto, a identidade é construída na prática (CIAMPA, 1991) e dentro de um contexto específico de ação. Considerando a identidade gerencial, esse contexto diz respeito às chamadas "relações de trabalho", que são aquelas que ocorrem entre empregadores e empregados em uma organização e são mediadas pelas relações de 
poder na e para a realização do trabalho (MELO, 1991). Em outras palavras, a empresa é vista como um lugar essencial de socialização, de construção da definição de si, dos outros e da representação sobre o mundo (SAINSAULIEU, 1997). É nesse sentido que Sainsaulieu (1997) e Dubar (1997) afirmam que se dá a construção da identidade pelo trabalho, ou seja, na relação com o outro e num contexto de relações de poder e de trabalho. Assim, a identidade é um processo político construído na ação, configurando um projeto sempre em andamento e a reconstruir. Nos termos de Dubar (1997, p. 105) a identidade é "o resultado simultaneamente estável e provisório, individual e coletivo, subjetivo e objetivo, biográfico e estrutural, dos diversos processos de socialização que, em conjunto, constroem os indivíduos e definem as instituições".

Os estudos sobre identidade gerencial, em especial, ainda são escassos. No entanto, alguns podem ser destacados. Pavlica e Thorpe (1998) analisam a identidade social de administradores tchecos, comparando-os com os britânicos. Eles partem do pressuposto de que o conceito de identidade é estreitamente relacionado ao de cultura e reconhecem que há diferenças significativas culturais entre os dois países. Como conseqüência, partem da hipótese de que tais diferenças afetam as respectivas práticas de gestão de duas maneiras: a forma pela qual os administradores acreditam que devem oficialmente conceituar e descrever seu papel; e o modo como os gestores individuais expressam e, talvez, modificam essa compreensão, à luz de suas experiências e visões (Pavlica; Thorpe, 1998).

Linstead e Thomas (2002) discutem o processo de construção da identidade de gerentes - homens e mulheres em uma empresa que passou por reestruturação. As autoras focam as formas como eles constroem sua identidade, entendida esta como sendo, muitas vezes, paradoxal, fluida, inconsistente e emergencial. Os gerentes entrevistados revelaram em depoimentos a natureza paradoxal de sua construção de identidade, realizada em termos de conjunção passado-futuro, no sentido de que posições assumidas em eventos prévios forneciam vantagens para eventos futuros. Em resumo, as autoras mostram o sentimento de fragilidade da identidade entre os gerentes entrevistados e a forma como eles procuram dar sentido e legitimidade a seus papéis (Linstead; Thomas, 2002).

Thomas e Davies (2005), nessa mesma direção, discutem a produção de significados e subjetividades no âmbito da chamada "nova gestão pública" britânica (New Public Management - NPM) e o modo como os indivíduos constroem suas identidades gerenciais. Em razão de o serviço público britânico passar por transformações há cerca de duas décadas, o que implica a redefinição de sua força de trabalho, as autoras entendem a NPM como um projeto identitário. Tal projeto é viabilizado por meio de novas tecnologias disciplinares desenhadas para inculcar novos valores, atitudes, prioridades e auto-entendimento entre os profissionais de serviço público. Na pesquisa das autoras, isso vem acarretando uma construção da identidade, ainda que de forma difusa e por vezes contraditória.

Hill (1993) demonstra empiricamente como os novos gerentes - aqueles que estão no começo de sua carreira, há cerca de um ano - constroem sua identidade ao longo do tempo e durante o exercício das atividades gerenciais. Em resumo, os indivíduos que assumem a função gerencial têm de lutar contra as tensões da transformação, abandonando atitudes e hábitos conservados e passando a experimentar novas maneiras de pensar e de ser.

O processo de construção da identidade envolve, basicamente, quatro aspectos fundamentais que ocorrem de forma seqüencial: "aprender o que significa ser gerente; desenvolver julgamentos interpessoais; adquirir autoconhecimento; e lutar contras as tensões e emoções" (HILL, 1993, p. 6).

Segundo a autora, o aspecto do aprendizado se refere à preparação para o exercício da função, à conciliação de expectativas (do próprio gerente, de colegas, subordinados e superiores) e ao caminho rumo à identidade gerencial. O novo gerente sai de um primeiro momento em que faz uso intenso de sua posição formal, focando prioritariamente em si mesmo e desconsiderando as mais diversas expectativas, até o momento em que começa a agir no sentido de assumir as responsabilidades básicas gerenciais: fixar agendas e estabelecer redes de trabalho. No segundo aspecto, o novo gerente desenvolve sua capacidade de julgamento interpessoal. Busca 
credibilidade e comprometimento em vez de meramente emitir ordens, passa a considerar a diversidade dos indivíduos, ou seja, a agir mais como líder. No terceiro aspecto, o gerente observa suas próprias fraquezas e virtudes e se pergunta por que ele se tornou gerente e se realmente reúne as condições para exercer a função. $\mathrm{O}$ indivíduo já sente, avalia e pensa como gerente. Ou seja, sua identidade está em plena transformação. Por fim, o último aspecto observado é a luta contra as tensões e emoções, no sentido de que assumir um cargo desta natureza implica lidar com uma série de tensões, medos, conflitos e ambigüidades, que são fontes permanentes de stress e afetam, inclusive, a vida familiar (HILL, 1993).

O que se percebe da pesquisa da autora é que a identidade é um processo permanente que não possui regras definidas, mas que guarda forte relação com o ambiente e com a organização na qual o indivíduo está inserido. Em outras palavras, envolve tanto um processo de socialização quanto de aprendizagem e implica grande envolvimento físico e psíquico.

Para se analisar o processo de construção identitária dos altos gestores das universidades federais, serão descritos, na seção seguinte, os passos metodológicos da pesquisa, seguidos da apresentação e da discussão dos resultados.

\section{Metodologia}

Nkomo e Cox Jr. (1999) afirmam que a pesquisa sobre identidade não permite uma mensuração discreta, pois os métodos quantitativos podem ser falhos em identificar o complexo significado e a construção da identidade. Nesse sentido, ressaltam ainda que as pesquisas tradicionais tendem a considerar a identidade mais como um fenômeno natural do que passageiro, o que, neste caso, implica assumir a identidade como fluídica e contraditória.

Considerando-se as singularidades e os aspectos subjetivos relativos ao trabalho dos gestores, a abordagem qualitativa apresenta melhores condições de responder às inquietações acerca da construção de suas identidades gerenciais, uma vez que possui um caráter basicamente compreensivo, ou seja, em exibindo as significações internas dos comportamentos, visa "apreender e explicitar o sentido da atividade social individual e coletiva enquanto realização de uma intenção" (BRUYNE et al., 1991, p. 139). Pressupõe-se, portanto, que os sujeitos "têm um conhecimento prático, de senso comum e representações relativamente elaboradas que formam uma concepção de vida e orientam suas ações individuais", ainda que isso não implique um conhecimento crítico que relacione os saberes específicos à totalidade e as experiências individuais ao contexto geral da sociedade (CHIZOTTI, 1991, p. 83). Em outras palavras, os sujeitos são dotados de uma consciência prática, de uma reflexividade que lhes permite "seguir em frente" e explicar suas ações (GIDDENS, 2002). É nesse sentido que a pesquisa qualitativa e seus métodos partem da perspectiva ou das ações do sujeito estudado (ALVESSON; SKÖLDBERG, 2000).

A coleta dos dados primários foi feita por meio da entrevista do tipo semi-estruturada, (TRIVIÑOS, 1987). Conforme a classificação de Flick (2003), foram utilizadas entrevistas episódicas, que permitem a combinação de convites para a narração de acontecimentos concretos com perguntas mais gerais e que busquem respostas mais amplas de relevância pontual, além do que pressupõem certa experiência dos entrevistados sobre as situações, acontecimentos ou processos estudados (FLICK, 2003).

Para a análise dos dados primários, recorreu-se basicamente à análise temática, que consiste em descobrir os "núcleos de sentido" que compõem a fala dos entrevistados. O tema é uma unidade de significação complexa, e sua validade é mais de ordem psicológica do que lingüística. Na análise de conteúdo, o tema é uma regra de recorte (BARDIN, 1977).

A análise temática foi realizada segundo os procedimentos propostos e utilizados por Melo $(2000,2001,2004)$ e colaboradores: 
a) preparação - as entrevistas foram transcritas integralmente segundo o roteiro de entrevista utilizado, agrupando-se as respostas de cada categoria para as respectivas questões;

b) tabulação quantitativa - identificação dos conteúdos das respostas e agrupamento segundo o tema da pergunta. Foram recuperadas as informações relativas aos objetivos da pesquisa, por meio de agrupamento de dados e construção de tabelas;

c) tabulação qualitativa - a partir da definição dos temas segundo os objetivos da pesquisa, foram selecionados extratos significativos das entrevistas, destacando-se a dimensão da fala dos entrevistados, sendo possível, desta forma, analisar-se o conjunto das referências ao tema e às suas ramificações.

Essa técnica privilegia, portanto, os conteúdos dos relatos, que são confrontados com os conceitos utilizados, o que permite avançar no conhecimento acerca da realidade específica dos gestores da alta administração das universidades federais localizadas em Minas Gerais.

\section{A construção da identidade gerencial dos gestores da alta administração: contexto, processo e configuração}

\section{Esquema de referência para uma discussão acerca da identidade gerencial}

Para a discussão acerca da construção da identidade gerencial, propõe-se um esquema que articula a identidade dos gestores tanto para si mesmos como para os outros. Ou seja, tal como eles se definem para si mesmos e para os outros e como os outros atores os identificam, segundo o postulado da dualidade no social (DUBAR, 1997). Nesse sentido, são considerados tanto os atores internos à instituição (pares, grupo político), que estão inseridos no contexto organizacional, quanto os externos (comunidade local, ANDIFES, MEC/SESu, Sistema Federal de Ensino Superior), que compõem o contexto institucional e o macroinstitucional.

A identidade para si é evidenciada a partir das categorias "trajetória pessoal e projeto identitário", "modo como a função gerencial é percebida e vivenciada" e "estratégias identitárias". Convém destacar que o foco central deste estudo reside na identidade gerencial do reitor, considerando-se tanto o seu próprio ponto de vista quanto o dos demais gestores. Do processo de construção da identidade, resulta uma determinada configuração identitária, que categoriza e caracteriza a identidade. A identidade para o outro é evidenciada a partir das categorias "reconhecimento interno" e "reconhecimento externo". A Figura 1, a seguir, demonstra o esquema para discussão da identidade gerencial dos gestores. 
Figura 1. Esquema para discussão da construção da identidade

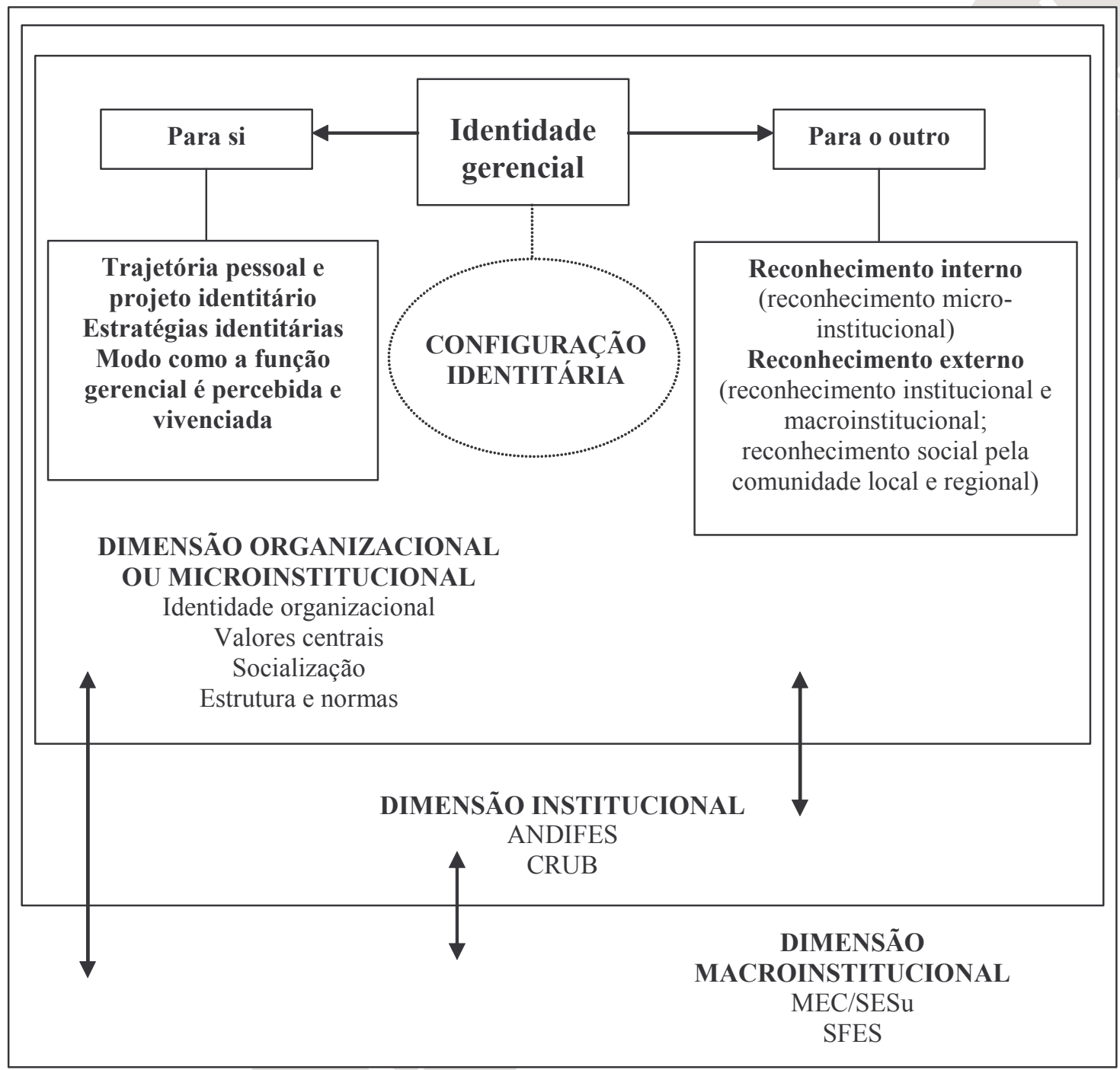




\section{Construção da identidade gerencial dos reitores: identidade para si}

\section{Trajetória pessoal e projeto identitário}

Os reitores se vêem basicamente como políticos, o que lhes confere um papel de representação perante a comunidade tanto interna quanto externa. Como representantes, pertencem, antes, a determinado grupo social, que pode ser tanto a comunidade universitária como um todo (representante externo) quanto determinado grupo político (representante interno). Segundo a teoria da identidade social, o conceito de identificação é fundamental, por se referir ao sentimento de pertencimento a uma determinada categoria (Brown, 1997; ashforth; MAEL, 1998).

Antes de se tornarem reitores, os indivíduos percorreram uma trajetória profissional, tanto acadêmica quanto gerencial. De modo geral, todos possuem uma vida acadêmica respeitável perante a comunidade, além de um percurso gerencial, com ocupação em diversos cargos da hierarquia organizacional: chefes de departamento, coordenadores de curso, representantes em conselhos, diretores de unidades acadêmicas, pró-reitores, etc.

Embora a idade não seja fator decisivo, o tempo na instituição foi significativo, pelo menos na amostra pesquisada. É como se o cargo de reitor fosse o "coroamento" da trajetória profissional. De certo modo, o critério "antiguidade" (experiência) parece ainda ter certo peso para que um indivíduo se candidatar a reitor ou a vice-reitor.

De outro lado, ocupar um cargo de gestor não é (apenas) uma questão de conseqüência natural de uma carreira, como a discussão anterior pode sugerir; há ainda a considerar certa dose de desejo e vontade de fazê-lo. A expressão "conseqüência natural" retira a possibilidade de escolha do sujeito da ação, reduzindo-o a um mero objeto da carreira. Ou seja, é como se a carreira escolhesse o indivíduo, e não o oposto. Embora os entrevistados ressaltem a opção inicial de serem professores e de desenvolverem uma carreira acadêmica (conforme vários depoimentos), o fato de se tornarem reitores pode fazer parte de um projeto de carreira gerencial que vem sendo construído ao longo do tempo. Daí, inclusive, o tempo médio de trabalho na instituição e a ocupação de diversos cargos gerenciais ao longo da trajetória profissional.

Parte-se do princípio de que qualquer pessoa pode sempre optar, em dado momento, positiva ou negativamente, por se tornar reitor (ou concorrer, pelo menos), a despeito das conseqüências de sua decisão, seja ela qual for. Para ocupar um cargo de reitor ou de vice-reitor, é necessário que o indivíduo tenha apoio político de determinado grupo de pessoas e que ele desenvolva, em conjunto com este grupo, um programa a ser proposto à comunidade numa campanha à eleição. Assim, não há a possibilidade de uma candidatura a reitorado ocorrer de forma impulsiva e impensada, dada a exposição pública a que o indivíduo se sujeita, em que sua experiência profissional e vida pessoal são colocadas abertamente em debate. Em suma, qualquer indivíduo tem conhecimento prévio de que, para se tornar reitor, há um percurso e um embate político pela frente. Daí considerar-se que a razão para que alguém se torne reitor esteja em um "projeto reflexivo do eu", (GIDDENS, 2002) uma decisão do sujeito. De outro lado, desejar e desempenhar são questões distintas. Se o indivíduo busca determinada identidade, ao tentar alcançá-la, pode ter sucesso ou não. Ou seja, ele pode vir a identificarse, ou não, com tal proposta. No entanto, é importante ressaltar que buscar uma identidade não é uma aventura despropositada. Ela é impregnada de história, de processos sociais (DUBAR, 1997; ELIAS, 1994) e de significado (CASTELLS, 2001).

\section{Modo como a função gerencial é percebida e vivenciada}

Embora possa ter havido alguma ambigüidade quanto ao desejo de se tornar reitor, é fato, pelos depoimentos, que a grande maioria afirma experimentar um grande prazer no exercício da função de dirigente máximo de suas instituições. A despeito do prazer do cargo e embora tenham clareza quanto ao fato de serem representantes dentro da universidade (contexto microinstitucional) e fora dela (contextos institucional e macroinstitucional), imediatamente surge uma tensão na construção da identidade: 
Você se depara então com barreiras impostas até pelo próprio governo, particularmente o Ministério da Educação. E você fica num fogo cruzado. Quer dizer, por um lado, como representante legítimo da comunidade acadêmica, no pleito dos seus anseios, uma série de demandas da comunidade acadêmica que, de uma certa forma, você representa. Mas, por outro lado, você ocupa um cargo executivo empossado pelo ministro. Então, você se vê na obrigação também de atuar em sintonia com a politica do próprio governo, e algumas delas vão de encontro, e não ao encontro dos anseios da comunidade. Então, é difícil. (Depoimento - Reitor)

A imagem de "fogo cruzado" sugere um conflito perturbador, pois o gestor se vê, basicamente, diante de um dilema: se atender a um determinado interesse, não atende a outro. Tal conflito não é trivial, pois quando perguntados sobre para quem trabalhavam, os reitores respondiam, em geral, que era primeiro para a comunidade universitária ou para o Conselho Universitário e, depois, para o MEC. Além disso, há que destacar - a partir de diversos depoimentos - que, nos últimos anos, os governos têm colocado em xeque os ideais históricos da universidade - em todo o mundo -, o que tem dificultado a ação gerencial dos reitores, na medida em os ideais de produtividade e resultado têm sido implementados pelos governos.

Os reitores definem-se, ao mesmo tempo, como políticos e gestores, e como alguém que ocupa um cargo de prestígio e status, o que confere ao indivíduo uma visibilidade social que the garante uma projeção no longo prazo, desde que este tenha o desejo de continuar seu percurso gerencial (e político) e fazer uso deste prestígio. Nesse sentido, há vários casos de ex-reitores (mencionados pelos entrevistados) que se candidatam a mandatos públicos de deputados ou de prefeitos, por exemplo, além de, freqüentemente, serem convidados para ocupar cargos de confiança em esferas municipais, estaduais ou federais.

Também se definem como professores. Na maioria dos casos, quando solicitados a se apresentar, o fizeram primeiramente como professor e, apenas mais adiante, como reitor, sendo que apenas dois deles se apresentaram inicialmente como tal. Este é um dado significativo, até porque o reitor é definido como o primus interparis1, ou seja, o primeiro entre os pares, isto é, o primeiro entre os professores. Assim, reforça o prestígio da função ao mesmo tempo em que valoriza a profissão docente, pois somente por meio dela e dos pares é possível tornar-se reitor.

Considerando a dimensão temporal da identidade, os reitores afirmam ressentirem-se da distância da sala de aula e das atividades acadêmicas, ainda que não vislumbrem a possibilidade de assumir cargos políticos futuros. A perspectiva de deixar a função gerencial acaba por provocar uma racionalização da função e do processo de ocupação, ao atribuir-lhe um caráter ou uma identidade passageira.

Então, eu acho que tem que voltar [...] porque a gente acaba se tornando excessivamente administrador, né? E você perde o foco do que é o trabalho como professor. No caso do professor, é bom que ele volte. (Depoimento - Reitor)

\section{A comunidade tem o direito de renovar. (Depoimento - Reitor)}

A racionalização também é expressa pelo discurso de que a política realmente democrática pressupõe a alternância do poder, diferentemente de sistemas autoritários ou despóticos.

Eu sempre trabalhei com o negócio "faltam tantos meses" [...] Eu tenho um sentido muito forte de tempo em política [...] E eu acho que é uma coisa importante essa idéia de que tem princípio, tem fim, tanto do ponto de vista democrático, porque o poder tem que se alternar. A grande coisa da democracia é o quê? Por que a democracia é boa? Porque ela te garante quando você não está no poder, não é? (risos). Por isso, lutamos pela democracia, porque nem sempre estaremos no poder. Os déspotas não precisam ter esse tipo de preocupação. (Depoimento - Reitor)

${ }^{1}$ Expressão mencionada por um dos reitores. 
À racionalização acrescenta-se a experiência subjetiva do tempo, expressa pela idéia da mortalidade.

É outro dia aqui e outro lá também. Isso é um pouco da experiência da mortalidade. Até quando você acaba o doutorado, é uma experiência de finalização. Você vai vestir uma outra pele daqui por diante. Então, terminar o reitorado também é uma experiência de mortalidade, é uma nova reencarnação que eu vou ter que me colocar [...] Eu sou uma pessoa que cultiva o sentido do tempo, porque eu sempre quis mudar. (Depoimento - Reitor)

O depoimento anterior coloca em evidência o caráter transitório e temporário da identidade, retirando-lhe o caráter de essência, ou núcleo imutável, apontando, inclusive, para o aspecto do envelhecimento físico e corporal, expresso pela "outra pele" e "reencarnação". De outro lado, do ponto de vista da racionalização, denota uma estratégia consciente de preparação para a assunção de novas identidades no futuro, cujo prazo é mais ou menos conhecido. Por meio deste mecanismo, o indivíduo articula seu projeto futuro com sua memória, com sua trajetória e com sua biografia.

\section{Estratégias identitárias}

No contexto específico de ação, a configuração identitária é fruto de uma negociação identitária que envolve tanto o processo de incorporação da identidade pelos próprios indivíduos quanto o de atribuição da identidade pelos agentes ou grupos que com eles interagem. Como nem sempre estes dois processos são coincidentes, pode haver um desacordo entre a identidade atribuída pelo outro e a identidade auto-atribuída, o que leva o indivíduo a adotar uma das duas estratégias identitárias: a transação objetiva entre os indivíduos e os outros, que visa a acomodar a identidade auto-atribuída à identidade para o outro; ou a transação subjetiva entre a necessidade de salvaguardar parte de suas identificações anteriores (identidades herdadas) e o desejo de construir para si uma identidade visada, procurando assimilar a identidade para o outro à identidade para si (DUBAR, 1997).

É assim que a identidade de reitor é negociada (DUBAR, 1997), uma vez que sua candidatura ao cargo não ocorre de forma totalmente autônoma, ainda que ele não seja um mero objeto dos imperativos funcionais e político-institucionais. Da mesma forma, o grupo que o apóia e do qual ele faz parte compreende que, uma vez reitor, o indivíduo não pode tão-somente agir em nome do grupo e de seus interesses, pois numa universidade (e em qualquer organização) os interesses são diversos e se constituem em diversos centros de poder, que impedem o reitor de agir, gerencial e politicamente, da forma autônoma como ele desejaria. Evidentemente, o gestor possui e faz uso de sua autoridade enquanto tal, mas esta é regulada pelos jogos de poder e pela estrutura organizacional colegiada.

A forma como o indivíduo vivencia e percebe seu trabalho gerencial, em termos de racionalidade, ambigüidades, angústias, dilemas, prazeres, facilidades e dificuldades, contribui e constitui efetivamente parte do processo de construção de sua identidade. Em outras palavras, o reitor está construindo sua identidade enquanto age como reitor. Quando age como reitor, ele é reitor. Assim, embora alguém possa afirmar: "Estou reitor, eu não sou reitor" -, na prática isso não é verdadeiro. O "estar reitor" é apenas uma constatação de que sua identidade é temporária. Enquanto o indivíduo "está reitor", ele é reitor.

Além disso, os reitores, enquanto tal, ao lidarem com diversas situações, sejam elas cotidianas ou episódicas, não apenas fazem uso de sua experiência e qualificação: precisam desenvolver uma série de atitudes e de comportamentos que também compõem sua identidade gerencial. Necessitam aprender a tomar certas decisões independentemente de suas posições particulares. De certo modo, precisam também aprender a agir como a organização. Como reitores, os indivíduos também adotam a estratégia (nem sempre consciente) de agir à semelhança de outras pessoas. Se, de um lado, esta semelhança pode se referir ao habitus, a busca de reconhecimento também passa pelos diversos processos de socialização, por meio dos quais o indivíduo vai moldando sua identidade, num processo em que ela é negociada. 
Por fim, a participação nos principais fóruns institucionais pode ser considerada um meio de construção da identidade, bem como uma reafirmação da mesma, o que leva a duas constatações. A primeira diz respeito ao fato de a participação em tais órgãos promover um amplo aprendizado na função gerencial, especialmente no que se refere à sua dimensão política. Nesse sentido, os depoimentos, em geral, confirmam que a participação na ANDIFES, por exemplo, é uma prática comum - e esperada, pois é uma instituição - e tem servido, principalmente nos últimos anos, à discussão e ao desenvolvimento das instituições, a partir da representação política que tem desempenhado. A segunda constatação se refere ao fato de que, ao participar desses fóruns, os reitores acabam por constituir uma "categoria" gerencial. Ou seja, além de serem reitores em suas universidades e perante a sociedade, somente a eles é permitido fazer parte de uma congregação de dirigentes que, em conjunto, representam suas instituições, deliberam e, em alguma medida, decidem os rumos da instituição universitária como um todo.

De modo a complementar a discussão acerca da construção da identidade do reitor, resta discorrer sobre sua identidade para o outro - no caso, os vice-reitores e os pró-reitores.

\section{Construção da identidade gerencial dos reitores: identidade para o outro}

As entrevistas apontam para uma convergência significativa (praticamente uma unanimidade) entre a identidade para si do reitor e a identidade atribuída pelos seus vice-reitores e pró-reitores. Ou seja, ser reitor é ser uma "mistura" de político e gestor:

O reitor tem que ser um representante da universidade... É interagir, articular a comunidade acadêmica, para ter uma interação com a sociedade [...] Também tem que interagir com as outras instituições de ensino, as empresas. Então, eu acho que o reitor é mais uma rainha da Inglaterra. Ele tem que promover a interação... um pessoa capaz de articular internamente a instituição de forma a interagir com a sociedade em geral. (Depoimento-Pró-Reitor)

Ressaltam-se os depoimentos a seguir, que vão mais longe:

Ele encarna o passado. Ele é responsável por uma memória da instituição. Ele é responsável por um projeto de instituição. Ele é responsável por aquilo de bom e de ruim que tem nessa instituição. Então, ele é um pouco a cara da instituição. (Depoimento - Vice-Reitor)

A hora que você assume o cargo de reitor você deixa de ser a pessoa e passa a ser o reitor. E isso faz com que você tenha que... todos os seus pensamentos, medidas, ações e direcionamentos sejam repensados. (Depoimento - Pró-Reitor)

Os discursos acima sugerem que o reitor é mais do que político e gestor. Ele é praticamente a universidade, uma figura deificada (aktouf, 1996), cuja dimensão humana é abstraída (“deixa de ser a pessoa”) e que simultaneamente reifica ("e passa a ser o reitor"; "a cara da instituição") a organização universitária (ashforth; MAEL, 1998), evocando sua força simbólica ("encarna o passado", "responsável por tudo bom e de ruim"). Alguns discursos tendem a criar, inclusive, uma aura de endeusamento que coloca a dimensão política como uma espécie de "disfunção" ou um obstáculo à gestão.

Eu acho que a primeira declaração que o reitor tem que fazer é a seguinte: "Gente, eu sou o reitor de todos, que venham a mim todos e vai ser igual". Mas ai tem a turma que diz "Não, eu te apoiei porque eu quero. Agora você me dê um tratamento diferenciado" (risos). (Depoimento - Pró-Reitor)

Pra mim, eu não tenho a menor dúvida que o [nome] é um representante legítimo, entendeu? Porque ele tem uma capacidade infinita, e olha que tem passado bons reitores aqui [...], mas o [nome do reitor] é ímpar, principalmente pela capacidade que ele tem de contornar problemas... Ele é capaz de apaziguar é... uma rebelião, tá? (Depoimento - Pró-Reitor) 
Embora a deificação e a reificação sejam processos subjetivos e simbólicos, acabam por gerar uma espécie de mecanismo de defesa racionalizado e justificado por uma lógica organizacional.

Às vezes, você tem que tomar decisões que vão afetar colegas teus, amigos, pessoas que freqüentam a sua casa. Mas tem que tomar e tem que ser compreendido. Você tem que fazer com que eles compreendam porque você está numa função. Não é o fulano quem está tomando a decisão, é o vicereitor que está tomando a decisão; porque as circunstâncias assim exigem dele. Ou ele vai tomar uma decisão para favorecer alguém porque é alguém. Então, tem que separar bem isso. (Depoimento Vice-Reitor)

O entrevistado afirma que não é o "fulano" (sujeito) que está decidindo, é o gestor (deificado). É como se ele dissesse: "Não sou eu, é outra pessoa". Neste momento ele invoca o que na sua visão seria a "essência" do seu "eu" (auto-identidade), distanciando-se de si (ELIAS, 1994), e a confronta com uma identidade que lhe é atribuída. Tal é a noção de "separação" que está embutida na fala do entrevistado e que consiste, de maneira ora clara, ora sublinear, no discurso da racionalidade gerencial. É a afirmação, com outras palavras, de que "você deixa de ser a pessoa e passa a ser o reitor".

Se todos reconhecem em seus reitores a identidade gerencial e política, também é verdadeiro que todos os entrevistados reconhecem que o reitor representa e pertence a um grupo político para se eleger e que, ao mesmo tempo, em assumindo, deve superar as divergências e direcionar a gestão para o bem-estar e para os objetivos da instituição, tal como colocado por um dos vice-reitores.

A gente chega num momento, e a gente sabe que isso é de universidade, que começa a haver os interesses para uma nova gestão. Então, as pedras começam a se mexer num xadrez. Olha, se fizer isso aqui vai favorecer "fulano" lá. Isso é ruim para a instituição. Eu acho que é ruim para o administrador principalmente. Ele começa a trabalhar com isso aqui... Ter que haver negociação é muito complicado. Não vivenciei isso ainda na função, mas estando de fora eu já percebi isso. Em certos momentos a instituição sofre com isso. Tem que haver o processo. Tem que haver a sucessão. Mas passou a sucessão tem que ser todo o mundo no mesmo barco. (Depoimento - Vice-Reitor)

O ideal da harmonia organizacional é um dos mitos da visão clássica gerencial, segundo o qual os conflitos são uma conseqüência indesejável dos processos de gestão, que seriam considerados uma tecnologia neutra para atingir objetivos coletivos (REED, 1997). Tal concepção de neutralidade informa que, embora a organização universitária seja encarada como constituída de diversos centros de poder, em que para se tornar um gestor é necessária uma grande articulação política coletiva, há um discurso do "vencedor" no sentido de que a harmonia deve ser um ideal a ser alcançado e mantido, pelo menos até a próxima eleição.

Subjacente ao discurso da harmonia e da democracia, está o problema estrutural que todo grupo enfrenta numa organização, isto é, o conflito entre o reconhecimento do desejo e o desejo do reconhecimento. Aqui, este conflito é resolvido via diferenciação (reconhecimento do desejo). Ou seja, no discurso dos indivíduos que pertencem a determinado grupo admitem-se multiplicidade e diferenças de opiniões e pensamentos, bem como se sustenta que o projeto coletivo será melhor se representar o resultado de negociações e discussões (ENRIQUEZ, 1994). Essa forma de ver o projeto coletivo não somente é pensada intelectualmente, como também é afetivamente sentida. No fundo, os gestores e seu grupo sentem, coletivamente, a mesma necessidade de transformar um sonho em realidade, buscando um meio de conseguir isso (ENRIQUEZ, 1994). Daí o depoimento de um dos pró-reitores:

Nós tínhamos um sonho em comum de como a universidade deveria ser construída, não é? Esse sonho comum, na verdade, é um projeto de universidade. Se não houver um projeto de universidade, eu não vejo nenhuma possibilidade do reitor sustentar nenhuma linha de trabalho, porque as pessoas aderem não à figura de um reitor; as pessoas aderem a uma proposta de universidade que aquele reitor, representando o grupo, defende, né? (Depoimento - Pró-Reitor) 
Por fim, a questão do mandato é encarada como uma espécie de treinamento para o desempenho de funções futuras socialmente importantes, invocando assim uma imagem gloriosa da figura do reitor.

Mas o reitor, pessoa que tem um mandato de uma Reitoria, é um profissional com uma experiência tal que o Estado, Estado como nação, o próprio Estado de Minas Gerais no nosso caso aqui, não poderia abdicar dessa experiência. Eu acho que uma pessoa que parte para uma experiência dessa, ele fica subutilizado se ele voltar lá só para a academia. Porque ele tem um treinamento. Ele é submetido aqui a uma atividade que ela é... se torna um treinamento para ele. Participar de uma reunião aqui, de uma rede de contatos imensa que ele estabelece. De repente, você põe num outro lugar em que ele vai começar a construir isso tudo de novo e tira e põe ele na sala de um laboratório outra vez [...] Então, eu acho que a sociedade prescinde disso. Não tem tantas pessoas assim com uma experiência dessas a ponto de você abrir mão e botar ele lá. [...] Então, a pessoa está pronta, e você deixa ele lá. Então, eu acho que qualquer outra função administrativa na atividade executiva, eu acho que cai bem para um ex-reitor. Uma administração em que ele pudesse estar contribuindo. (Depoimento - Vice-Reitor)

O discurso sugere que, ao mesmo tempo em que ser reitor é uma espécie de recompensa pela trajetória de sucesso do indivíduo na instituição, retornar à identidade anterior (de professor) seria uma espécie de desperdício (do ponto de vista institucional) e um retrocesso (do ponto de vista pessoal). Sugere, ainda, que ser professor é "pouco" ou, antes, que ser gestor é "mais", quando o entrevistado afirma que o reitor não pode voltar "só" para a academia, que ele não deve ser confinado ao "laboratório", que agora que ele "está pronto" será "deixado lá". Na prática, a narrativa anterior acaba por indicar:

- a necessidade de se aproveitar a experiência adquirida em função gerencial pública (subutilização e necessidade da sociedade);

- uma estratégia discursiva que cria uma narrativa pública e conceitual (SOMERS; GIBSON, 1997) que legitima e reforça a prática social da gestão e de suas ações, bem como contribui para o reforço ou para a reposição da identidade (CIAMPA, 1991) gerencial dos indivíduos (“[...] Então a pessoa está pronta $[\ldots] ")$;

- o reconhecimento (e o reforço) de uma comunidade (gerencial) cujos valores, ideais e objetivos devem ser mantidos institucionalmente, garantindo prestígio, status e reconhecimento social (“[...] qualquer outra função administrativa na atividade executiva, eu acho que cai bem para um ex-reitor [...]).

Os depoimentos dos vice-reitores e pró-reitores, em seu conjunto, representam, portanto, narrativas (SOMERS; GIBSON, 1997) que, ao mesmo tempo em que denotam, reproduzem e reforçam elementos, valores e preceitos que definem a identidade organizacional, servem para atribuir e legitimar ações individuais na construção (negociação) de suas identidades (no caso, gerencial).

Embora outros atores sociais institucionais não tenham sido questionados, evidencia-se o reconhecimento do papel formal prescrito e atribuído ao reitor. No contexto microinstitucional, o simples fato de o reitor ter sido eleito já é um sinal deste reconhecimento. Da mesma forma, o processo se dá nos contextos institucional (órgãos de representação) e macroinstitucional (esfera governamental). Se formalmente seu papel é aceito e admitido, é no contexto da ação e da prática social da gestão que sua identidade será construída.

\section{Conclusão}

Atualmente, os gestores encontram-se num contexto de ambigüidades e de dilemas que, no caso particular da universidade, antepõe os ideais históricos da universidade (liberdade de pensamento e de expressão por meio do ensino, pesquisa e extensão, pluralismo de idéias e busca do conhecimento) aos ideais econômicos de produtividade, eficiência e resultados. Está em curso uma tentativa de se inculcarem novos valores, atitudes e prioridades entre os gestores universitários, no sentido de projetar uma identidade gerencial empreendedora revestida dos ideais empresariais de performance e resultado. Não se trata apenas de uma imposição 
governamental, mas de uma dinâmica macrossocial mais ampla, em que discursos e ideais contraditórios disputam espaços, numa luta desigual. Ou seja, o projeto identitário da universidade e, por conseguinte, de seus gestores, está inserido numa macrorrelação de poder.

Nesse contexto, os indivíduos buscam se posicionar, mas se deparam com as ambigüidades e ambivalências que lhes são colocadas por aquele embate, resultando numa identidade múltipla (políticos, gestores e professores), frágil e, por vezes, contraditória (na medida em que deve articular e negociar interesses diversos). Não se trata de afirmar que o reitor não seja ou não deva agir como gestor. Ao contrário, a universidade é também um espaço organizacional e, como tal, não pode prescindir de ter suas atividades gerenciadas. Com efeito, os gestores vivenciam uma etapa na construção de suas identidades que pode ser enunciada como uma "fase crítica de posicionamento", pois envolve tanto as identidades a eles atribuídas pelos diversos atores sociais - externos e internos à universidade - quanto aquelas que eles atribuem ou pretendem atribuir a si próprios, que são em grande medida conflitantes. Isso implica afirmar que a todo o processo de construção de identidade está atrelada uma determinada configuração identitária, que é a base das negociações e um resultado desejado em determinado contexto e sistema de ação, e durante algum período de tempo. Na prática, a identidade desejada pode diferir da identidade realizada, o que implica fraturas em sua configuração (DUBAR, 1997).

Assim, tornou-se fundamental compreender quais são as representações sobre a função gerencial, como os indivíduos lidam com as mesmas e como elas contribuem para organizar a construção da identidade dos gestores da alta administração das universidades, no contexto da prática social da gestão, que é estruturada pelas relações de poder. Ou seja, como a identidade gerencial é construída. Portanto, retomando o objetivo desse estudo, evidenciam-se os principais resultados:

- a natureza e as características principais do trabalho dos reitores entrevistados convergem para o que mostram ou preconizam as publicações acerca do trabalho do gerente privado e público. No entanto, evidencia-se um forte simbolismo inerente ao cargo, dado o caráter institucional da universidade;

- os indivíduos entrevistados assumiram a função gerencial em função de seus desejos de reconhecimento, realização, poder e prestígio social;

- os reitores e vice-reitores percebem reciprocamente seu trabalho como complexo, difícil e desgastante, pois exige deles grande dedicação e envolvimento emocional. Os pró-reitores percebem seu trabalho como de natureza mais técnica do que política. No conjunto vivenciam seu trabalho de forma comprometida, dado o envolvimento político que os congrega;

- a identidade gerencial é construída em dois estágios distintos, mas complementares: quando da eleição e do exercício da função gerencial;

- no processo de construção de suas identidades gerenciais, tanto na fase eleitoral como no exercício da função gerencial, os reitores primeiramente estabelecem redes internas e externas de interesses e de trabalho, para depois negociar e fixar sua agenda de trabalho, contrariamente aos achados de Hill (1993) em seu estudo sobre os novos gerentes.

Os resultados apontam para a construção de uma identidade reconhecida socialmente, cuja força se faz mais presente nos contextos microinstitucional e institucional. Nas últimas décadas, o prestígio e o status de gestor universitário - reitor, especialmente - vêm perdendo reconhecimento social perante a esfera governamental, embora, em cidades de menor porte, os gestores ainda os possuam.

Assim, os gestores vêm construindo suas identidades num contexto macrossocial mais amplo e em transformação. Os reitores, em especial, encontram-se diante de uma situação quase inconciliável devido às forças e aos jogos de poder, com o qual têm de aprender a conviver para poder exercer sua ação gerencial. Ação gerencial esta que, para indivíduos investidos em mandatos, tem seus dias contados para começar e para acabar. 


\section{Referências}

AKTOUF, Omar. A administração da excelência: da deificação do dirigente à reificação do empregado (ou os estragos do dilema do Rei Lear nas organizações). In: DAVEL \& VASCONCELOS. "Recursos" Humanos e subjetividade. Petrópolis: Vozes, 1996.

ALVESSON, Mats; SKÖLDBERG, Kaj. Reflexive methodology: new vistas for qualitative research. London: Sage, 2000.

BARDIN, Laurence. Análise de conteúdo. Lisboa: Edições 70, 1977.

BRUYNE, Paul de ; HERMAN, Jacques ; SCHOUTHEETE, Marc de. Dinâmica da pesquisa em ciências sociais. 5. ed. Rio de Janeiro: Francisco Alves, 1991.

CHANLAT, Jean-François. Ciências sociais e management: reconciliando o econômico e o social. São Paulo: Atlas, 2000.

CIAMPA, Antonio da Costa. A estória do Severino e a história da Severina: um ensaio de psicologia social. São Paulo: Brasiliense, 2001.7. reimpressão de 1987.

Identidade. In: LANE, Silvia T. M.; CODO, Wanderley (Orgs.). Psicologia social: o homem em movimento. 9. ed. São Paulo: Brasiliense, 1991.

DAVEL, Eduardo, MELO, Marlene Catarina de Oliveira Lopes. Reflexividade e a dinâmica da ação gerencial. In: (Org.). Gerência em ação: singularidades e dilemas do trabalho gerencial. Rio de Janeiro: FGV Editora, 2005.

DAVEL, Eduardo; VERGARA, Sylvia Constant. Gestão com pessoas e subjetividade. São Paulo: Atlas, 2001.

DUBAR, Claude. A socialização: construção das identidades sociais e profissionais. Porto: Porto, 1997.

ERIKSON, Erik H. Identidade: juventude e crise. Rio de Janeiro: Guanabara, 1987.

ÉSTHER, Angelo Brigato; MELO, Marlene Catarina de Oliveira Lopes. Contexto, Atuação e Dilemas do Trabalho Gerencial. In: Encontro Nacional de Estudos Organizacionais, 3, 2004, Anais. Atibaia: ANPAD, 2004.

FLICK, Uwe. Entrevista episódica. In: BAUER, Martin W.; GASKELL, George. Pesquisa qualitativa com texto, imagem e som: um manual prático. Petrópolis: Vozes, 2003, p. 114-136.

GIDDENS, Anthony. Modernidade e identidade. Rio de Janeiro: Jorge Zahar Editor, 2002.

HILL, Linda. Os novos gerentes: assumindo uma nova identidade. São Paulo: Makron Books, 1993.

LINSTEAD, Alison; THOMAS, Robyn. "What do you want from me?" a poststructuralist feminist reading of middle mangers' identities. Culture and organization, v. 8, n. 1, 2002, p. 1-20.

MELO, Marlene Catarina de Oliveira Lopes. As estratégias do trabalhador informático nas relações de trabalho. 1991. Tese (Professor Titular) - Faculdade de Ciências Econômicas, Belo Horizonte, 1991.

Competitividade e novas tecnologias de gestão: revisitando a função gerencial. Belo Horizonte: CEPEAD, 1994a (Relatório de Pesquisa/Sebrae).

Dificuldades de implementação de uma nova função gerencial: alguns resultados e reflexões. In: Reunião Anual da Associação Nacional dos Programas de Pós-Graduação em Administração, Anais..., 18., 1994b. p. 347-359.

. 0 gerente e a função gerencial nas organizações pós-reestruturação produtiva. In: Encontro Nacional de Estudos do Trabalho, Anais..., 6., São Paulo: ABET, 1999.

(Coord.). 0 espaço da gerência feminina: desafios de gênero e da função em instituições financeiras. Belo Horizonte: CEPEAD/FACE/UFMG, 2000 (Relatório de Pesquisa).

(Coord.). Desafios da gerência e liderança em contextos diferenciados de reestruturação: a gerência feminina em instituições financeiras e a construção de liderança em redes organizacionais. Belo Horizonte: CEPEAD/FACE/UFMG, 2001 (Relatório de Pesquisa). 
(Coord.). Gestor e gerência em organizações públicas e privadas: questões reestruturação, de gênero e descentralização. Belo Horizonte: CEPEAD/FACE/UFMG, 2004 (Relatório de Pesquisa).

NKOMO, Stella M.; COX Jr., Taylor. Diversidade e identidade nas organizações. In: CALDAS, Miguel; FACHIN, Roberto; FISCHER, Tânia (Orgs.). Handbook de estudos organizacionais: modelos de análise e novas questões em estudos organizacionais. V. 1. São Paulo: Atlas, 1998. p. 334-360.

PAVLICA, Karel, THORPE, Richard. Manager's perceptions of their identity: a comparative study between the Czech Republic and Britain. In: British Journal of Management, v. 9, 1998. p.133-149.

REED, Michael. Sociologia da gestão. Oeiras: Celta, 1997.

SAINSAULIEU, Renaud. Sociologia da empresa: organização, cultura e desenvolvimento. Lisboa: Instituto Piaget, 1997.

THOMAS, Robyn, DAVIES, Annette. Theorizing the micro-politics of resistance: New Public Management and managerial identities in the UK public services. Organization Studies, v. 26, n. 5, 2005. p. 683-706.

TRIVIÑOS, Augusto Nibaldo Silva. Introdução à pesquisa em ciências sociais: a pesquisa qualitativa em educação. São Paulo: Atlas, 1987. 